(1) CrossMark

Cite this: RSC Adv., 2014, 4, 40421

Received 25th June 2014

Accepted 21st August 2014

DOI: $10.1039 / \mathrm{c} 4 \mathrm{ra06} 220 \mathrm{e}$

www.rsc.org/advances

\section{Glycol based plasticisers for salt modified starch}

\author{
Andrew P. Abbott, ${ }^{\text {a }}$ Tariq Z. Abolibda, ${ }^{\text {a }}$ Stefan J. Davis, ${ }^{a}$ Franziska Emmerling, ${ }^{\text {b }}$ \\ Denis Lourdin, ${ }^{c}$ Eric Leroy ${ }^{d}$ and William R. Wise ${ }^{a}$
}

\begin{abstract}
Starch is one of the most common and easily obtained natural polymers, making it attractive as a potential bio-based alternative to synthetic polymers. This study shows that a simple quaternary ammonium salt combined with urea or glycols forms effective modifiers that produce flexible plastics with good mechanical properties that are comparable to some polyolefin plastics. The processing conditions are shown to significantly affect the structure of the polymer which has a concomitant effect upon the mechanical and physical properties of the resulting plastic. Using a glycerol based modifier results in a totally sustainable and biodegradable material which can be injection moulded.
\end{abstract}

\section{Introduction}

Starch is a ubiquitous carbohydrate found in most plants. It is hygroscopic and crystalline due to an extensive network of intraand inter-molecular hydrogen bonds. Numerous studies have shown that native starch granules can be melt processed in the presence of water and other polar hydrogen bonding molecules such as alcohols and amides. ${ }^{1}$ Such molecules lower the melting temperature of starch's crystalline structure. Industrial thermomechanical processes, such as extrusion, can thus be applied in order to obtain a thermoplastic material. ${ }^{1}$ The same hydrogen bonding molecules thus act as plasticisers of the resulting amorphous polymer network, modifying its physical properties, in particular the glass transition temperature. ${ }^{2}$ Other recent reviews give a more detailed summary of advances in this field. ${ }^{3,4}$

It is noteworthy that contrary to petroleum based plastics, native starch granules cannot be completely molten just by increasing the temperature. ${ }^{5}$ Unless a minimum specific mechanical energy (typically $100 \mathrm{~kJ} \mathrm{~kg}^{-1}$ ) is applied by intense shearing, a "phantom" structure of the granules may remain in the final material. Nevertheless, too much mechanical energy may also result in a strong degradation of the starch macromolecules. ${ }^{6}$ Thus, twin screw extrusion is generally preferred in order to fine tune the thermomechanical history of the material and efficient modelling software have been developed to optimise the process. ${ }^{7}$ Nevertheless, remaining issues associated with the thermoplastic starch (TPS) materials obtained with

${ }^{a}$ Chemistry Department, University of Leicester, LE1 7RH, Leicester, UK. E-mail: apa1@le.ac.uk

${ }^{b} B A M$ Bundesanstalt für Materialforschung und -prüfung 1.3 Strukturanalytik, Richard-Willstätter-Str. 11, D-12489, Berlin-Adlershof, Germany

${ }^{c}$ UR1268 Biopolymères Interactions Assemblages, INRA, F-44300 Nantes, France

${ }^{d}$ LUNAM Université, CNRS, GEPEA, UMR 6144, CRTT, 37, boulevard de l'Université, 44606 St Nazaire Cedex, France conventional plasticisers are that they are not particularly strong and they exhibit a tendency to recrystallise with time and become brittle.

Recently, it was shown by the authors that liquid salts, ${ }^{\mathbf{8} 9}$ such as ionic liquids or deep eutectic solvents with polar modifiers like urea, can be used as efficient new plasticisers of starch. Significant reductions of the necessary specific mechanical energy needed for melt processing were observed. ${ }^{9}$ In addition, materials with improved tensile strength which do not recrystallise rapidly could be produced..$^{8,9}$ It was shown that the water sensitivity of starch materials could be decreased in presence of the ionic plasticisers. ${ }^{\mathbf{1 0 , 1 1}}$ These materials behave like true thermoplastics and can be recycled without significant loss of mechanical integrity. The thermoplastic starch has also been used as a binder for wood particles to make a thermoplastic material which can be recycled. ${ }^{10}$

The current study aimed to optimise the components of the deep eutectic solvents by replacing the urea component with ethylene glycol or glycerol. Mixtures of glycerol and quaternary ammonium salts have been shown to have enhanced solvent properties due to decreased viscosity and increased hydrogen bonding ability. ${ }^{\mathbf{1 1}}$ They are also of note as their synthesis has a Sheldon E-factor of zero. Here it is demonstrated that the plasticiser and processing conditions significantly change the properties of the material and this is explained in terms of the crystallinity.

\section{Experimental}

Corn flour (Weikfield Foods Ltd.) was used as received with no additional drying steps unless specified. Glycerol, urea, ethylene glycol and choline chloride (all Sigma Aldrich $>99 \%$ ) were used as received. The starch, glycerol and choline chloride were mixed in the appropriate amounts using a Kenwood BL330 Series food processor and the mixture placed in an oven (Thermo Scientific Heraeus) at $50{ }^{\circ} \mathrm{C}$ for three hours. If the 
modifier liquids were prepared in advance then a previously described method was used ${ }^{\mathbf{1 1}}$ and the appropriate amount of starch and modifier was mixed (Kenwood BL330 Series food processor) then baked in oven at $50{ }^{\circ} \mathrm{C}$ for 3 hours. In both cases the final baked mixture was placed in a sealed bag to be extruded or pressed.

The mixture of starch with glycerol and choline chloride was extruded by a Prism TSE-24 TC co-rotating twin screw $(20$ L/D) extruder with a Prism volumetric feeder and an air swept facecut pelletising system. The extruder has 5 temperature controlled zones; the first was held at $80{ }^{\circ} \mathrm{C}$ and the other 4 were set as a group between $100{ }^{\circ} \mathrm{C}$ to $160{ }^{\circ} \mathrm{C}$ depending on the experiment; the feed zone was maintained at ca. $15{ }^{\circ} \mathrm{C}$ with water cooling. The screw profile was as follows: $4.5 \mathrm{~L} / \mathrm{D}$ conveying screw, $0.75 \mathrm{~L} / \mathrm{D} 30^{\circ}$ kneading, $0.75 \mathrm{~L} / \mathrm{D} 60^{\circ}$ kneading, $1.25 \mathrm{~L} / \mathrm{D} 90^{\circ}$ kneading, $7 \mathrm{~L} / \mathrm{D}$ conveying screw, $0.5 \mathrm{~L} / \mathrm{D} 60^{\circ}$ kneading, 0.75 L/D 90 kneading, $3 \mathrm{~L} / \mathrm{D}$ conveying screw, 1.5 L/D single lead discharge screws. The speed was set to approximately $100 \mathrm{rpm}$, at which the die pressure was $c a$. 20 bar. The air swept face-cut pelletising system's blades were set at $95 \mathrm{rpm}$ with only one blade set-up to cut.

The powdered mixture or extruded pellets were placed between two copper plates lined with non-stick silicone sheets with a $1 \mathrm{~mm}$ copper separator ( $9 \mathrm{~cm}$ square aperture). The sandwich was then placed in a hydraulic press (Fontune Grotnes Laboratory Press TH400) and a force of $110 \mathrm{kN}$ was placed on the sample for 10 minutes at the specified temperature. The sample was then cooled back to room temperature (water circulation) in 5-10 $\mathrm{min}$ in the press with the force still applied. The cooled sample was removed from the press and the mould before using a mechanical 'dog bone' press (Ceast Hollow Die Punch, Type 6051) to cut test shapes (test area size: $L$ $=30 \mathrm{~mm}, W=4 \mathrm{~mm}, D=1 \mathrm{~mm})$.

The tensile testing of $\mathrm{dog}$ bone shaped samples was carried out using an Instron 3343 tensile apparatus (Instron Ltd, Assembled, USA) with a load cell of $500 \mathrm{~N}$. The material strain and stress was controlled by Instron Bluehill 2 software and average values were taken from 8 or more samples. In every case the thickness of each sample was measured using a micrometre and subjected to a strain rate between $2-10 \mathrm{~mm} \mathrm{~min}^{-1}$.

Differential Scanning Calorimetry (DSC) was used to evaluate the thermal transitions. A Q100 DSC (T.A. Instruments) was used, with InOx sealed pans. A first heating stage from 20 to $95{ }^{\circ} \mathrm{C}$ at $3{ }^{\circ} \mathrm{C} \min ^{-1}$ was made to erase the sample history, the sample was then cooled to $-40^{\circ} \mathrm{C}$ and heated again to $120^{\circ} \mathrm{C}$ at $3{ }^{\circ} \mathrm{C} \mathrm{min}{ }^{-1}$. The glass transition temperature $\left(T_{\mathrm{g}}\right)$ was evaluated from the thermogram recorded during the second heating ramp, defined as the midpoint of the heat capacity increase. Surface analysis was carried out using scanning electron microscopy (SEM) a (Phillips XL30 ESEM) instrument with an accelerator voltage of between 15 and $20 \mathrm{keV}$, giving an average beam current of $c a .120 \mu \mathrm{A}$.

The determination of mechanical relaxation was measured on a dynamic mechanical analyser DMA50 (Metravib, Lyon, France). A tensile mode was used with a dynamic strain imposed of $0.01 \%$. The temperature ramp was fixed from $-40{ }^{\circ} \mathrm{C}$ to $180{ }^{\circ} \mathrm{C}$ at $3{ }^{\circ} \mathrm{C} \mathrm{min}^{-1}$. Samples were coated with hydrophobic grease in order to limit dehydration during the test.

Powder X-ray diffraction (XRD) was conducted using a using a Bruker D5000 with copper $\mathrm{K}_{\theta 1,2}$-radiation. The assignment of the different phases present in the samples was carried out using the Powder Diffraction File (PDF) from the International Centre for Diffraction Data (ICDD). The search-match routine implemented in the software EVA (Bruker AXS, Karlsruhe, Germany) was used to identify the crystalline phases. The diffraction patterns were collected using the following conditions: $2 \theta$ range: $5^{\circ}-60^{\circ}$, step size: $0.02^{\circ}$, step time: $15 \mathrm{~s}$ (long measurement) taken over 11.5 hours; all samples were measured on conventional sample holders with no adhesive substances being used. The diffraction pattern of the sample "corn starch" can be assigned to the data base entry for corn starch (PDF 39-1911). Injection moulding was carried out on a Demag Ergotech 80-310 Compact 80 ton plastic injection mould machine operating at $200{ }^{\circ} \mathrm{C}$ and $60 \mathrm{bar}$.

\section{Result and discussion}

\section{Effect of hydrogen bond donor (HBD)}

Previously it has been shown that mixtures of choline chloride and urea act as effective plasticisers for corn starch and it was shown that strengths similar to high density polyethylene could be achieved. ${ }^{8}$ In the current study comparisons are made replacing urea by ethylene glycol and separately with glycerol. Table 1 shows the ultimate tensile stress (UTS), percent elongation at break and chordal modulus obtained by measurements taken from 10 samples. Fig. 1 shows representative stress-strain curves for these mixtures containing $75 \mathrm{wt} \%$ starch and 25 wt $\%$ modifier; these compositions were optimised in previous studies. ${ }^{\mathbf{1 2}}$

It can clearly be seen that all three HBDs act as different types of plasticiser. The glycerol based plastics are stronger, less

Table 1 Effect of hydrogen bond donor on the strength, ductility and chordal modulus of various extruded thermoplastic starch samples. Samples extruded at $120^{\circ} \mathrm{C}, 100 \mathrm{rpm}$ and a die pressure of $\mathrm{ca}$. 20 bar before being pressed at $145^{\circ} \mathrm{C}, 110 \mathrm{kN}$ for $10 \mathrm{~min}$. Testing has extension rate of $2 \mathrm{~mm} \mathrm{~min} \mathrm{~m}^{-1}$

\begin{tabular}{lccc}
\hline Composition starch: ChCl:HBD & Young modulus (MPa) & Tensile strength (MPa) & Elongation (\%) \\
\hline HBD $=$ glycerol & $281 \pm 42$ & $16.8 \pm 0.55$ & $6.10 \pm 1.03$ \\
HBD = urea & $94 \pm 41$ & $13.1 \pm 2.01$ & $15.4 \pm 4.11$ \\
HBD = ethylene glycol & $17 \pm 14$ & $6.04 \pm 0.41$ & $39.1 \pm 13.7$ \\
Low density polyethylene & $200-400$ & $8-12$ & 600
\end{tabular}




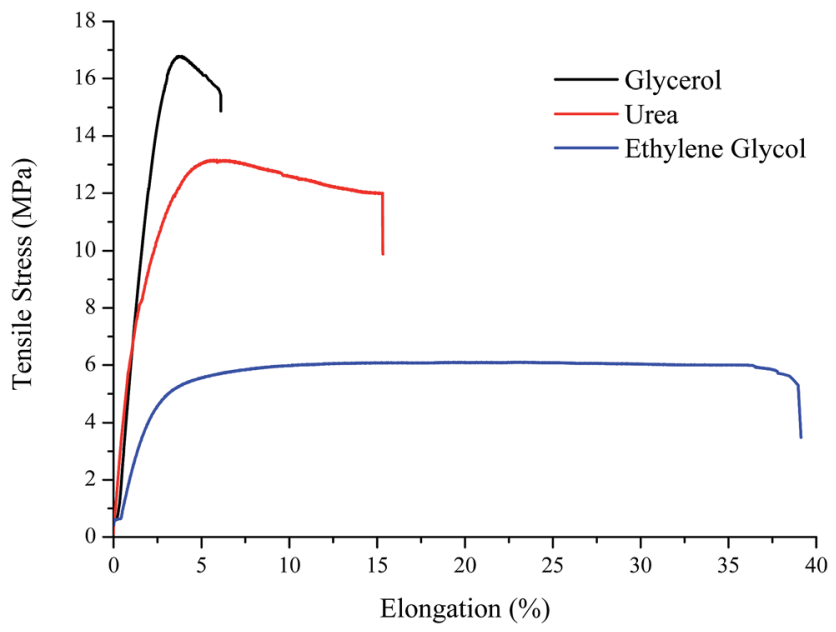

Fig. 1 Representative stress-strain curves for starch modified with choline chloride with either; urea, ethylene glycol or glycerol. Samples were extruded at $130{ }^{\circ} \mathrm{C}, 100 \mathrm{rpm}$ and a die pressure of ca. 20 bar before being pressed at $145{ }^{\circ} \mathrm{C}, 110 \mathrm{kN}$ for $10 \mathrm{~min}$. Testing has extension rate of $2 \mathrm{~mm} \mathrm{~min}^{-1}$.

flexible and more brittle and this is almost certainly due to the ability of glycerol to act as a 3 dimensional hydrogen bond former due to having three functional groups. Ethylene glycol produces plastics which are more ductile but less strong. Glycerol is beneficial as it is a waste by-product from the transesterification and saponification of oils and fats which are associated with biodiesel and soap manufacture. ${ }^{13}$ In all subsequent experiments the starch plasticiser composition used was 75.0 wt\% starch 10.8 wt\% choline chloride and $14.2 \mathrm{wt} \%$ glycerol. All of the materials described below can be reground and reprocessed without significant loss of mechanical strength as was previously reported for the urea based salt modified starch. ${ }^{8}$

There are many factors which could affect the strength of the starch materials and these include the pre-treatment, composition, water content, extrusion temperature, residence time in the extruder, pressing time and pressing temperature.

\section{Effect of pre-treatment}

Baking the starch after it is mixed with the plasticiser is required to dry the mixture from the absorbed moisture. ${ }^{8}$ If the mixture contains too much moisture the resultant plastic is mechanically compromised but if it is totally dry then the

Table 2 The effect of pre-baking time on the mixture of corn flour, glycerol and choline chloride before pressing. These samples were not extruded but directly pressed at $140{ }^{\circ} \mathrm{C}$ with $110 \mathrm{kN}$

\begin{tabular}{llll}
\hline Baking time (hours) & $\begin{array}{l}\text { Tensile stress } \\
(\mathrm{MPa})\end{array}$ & $\begin{array}{l}\text { True strain } \\
\left(\mathrm{mm} \mathrm{mm}^{-1}\right)\end{array}$ & Water (wt\%) \\
\hline 1 & 1.60 & 0.304 & 8.9 \\
2 & 4.86 & 0.107 & 8.6 \\
3 & 6.01 & 0.045 & 8.2 \\
4 & n/a & n/a & 7.8
\end{tabular}

plastic will not form. The original unbaked mixture contained $9.1 \mathrm{wt} \%$ moisture. Table 2 shows the maximum tensile strength and the tensile strain of TPS for different drying times in an oven at $50{ }^{\circ} \mathrm{C}$. The strongest un-extruded TPS is the mixture that is dried for three hours in an oven at $50{ }^{\circ} \mathrm{C}$; giving a UTS of 6.01 MPa. It is possible that if the starch is too dry then it is too crystalline to allow the glycerol and salt to penetrate the granular structure and plasticise it. It appears from Table 2 that the optimum water content of the pre-extruded mixture is $8.2 \mathrm{wt} \%$.

\section{The effect of extrusion temperature and compression temperature/time}

The starch-plasticiser blends were heated and mixed during both the extrusion and compression-moulding stages. It was previously shown that extrusion increases the strength by up to a factor of 5 however the extrusion conditions will affect the ability of the plasticisers to permeate into the starch structure affecting the water content and hence the crystallinity of the samples. ${ }^{8}$ Fig. 2 shows the effect of extrusion temperature and compression temperature on the UTS and tensile strain. In most cases the pressing temperature has little effect upon the UTS or tensile strain which demonstrates the importance of the shear mixing of the components during the extrusion process. Once the pellets have been formed, the pressing stage is just fusing the individual grains together. It can be seen that increasing the extrusion temperature increases the tensile strength, but the biggest improvement in material properties occurs between 110 and $130{ }^{\circ} \mathrm{C}$, Fig. 2a.

Dogossy and Cziagany investigated the tensile strength of TPS, modified by glycerol or maltitol extruded at 90, 105 and 120 ${ }^{\circ} \mathrm{C}$ and found that the UTS was about $4 \mathrm{MPa} .{ }^{14}$ Adding the salt to the plasticiser mixture increases the UTS to $6 \mathrm{MPa}$ even for the non-extruded TPS. Extruding the mixture at $120{ }^{\circ} \mathrm{C}$ increased the UTS to approximately $13 \mathrm{MPa}$ which is a three-fold increase over pure glycerol. Increasing the extrusion temperature increases the UTS and decreases the tensile strain i.e. materials decrease their flexibility and ductility and become more brittle.

Fig. 3 demonstrates that an increase in extrusion temperature also changes the physical appearance of the plastic; both the pellets and the plastic sheet in Fig. $3 \mathrm{~g}$ are clearly more yellow than those of Fig. 3a. This is potentially due to starch degradation and caramelisation of the sugars as a result of the processing heat in the extruder; however these degradation products were in too low a concentration to be detected by a number of analytical methods.

The time that the sample spends in the compression mould does not significantly impact the tensile strength of the sheet. The strength was roughly constant when pressed between one and twenty minutes. This shows that once the sample has been extruded the homogenisation is complete and the pressing (or injection moulding) simply needs to melt the extruded pellets sufficiently to let the sample flow.

\section{The effect of residence time in extruder}

The temperature of the different zones in the extruder is only one parameter influencing the efficiency of the plasticiser to 

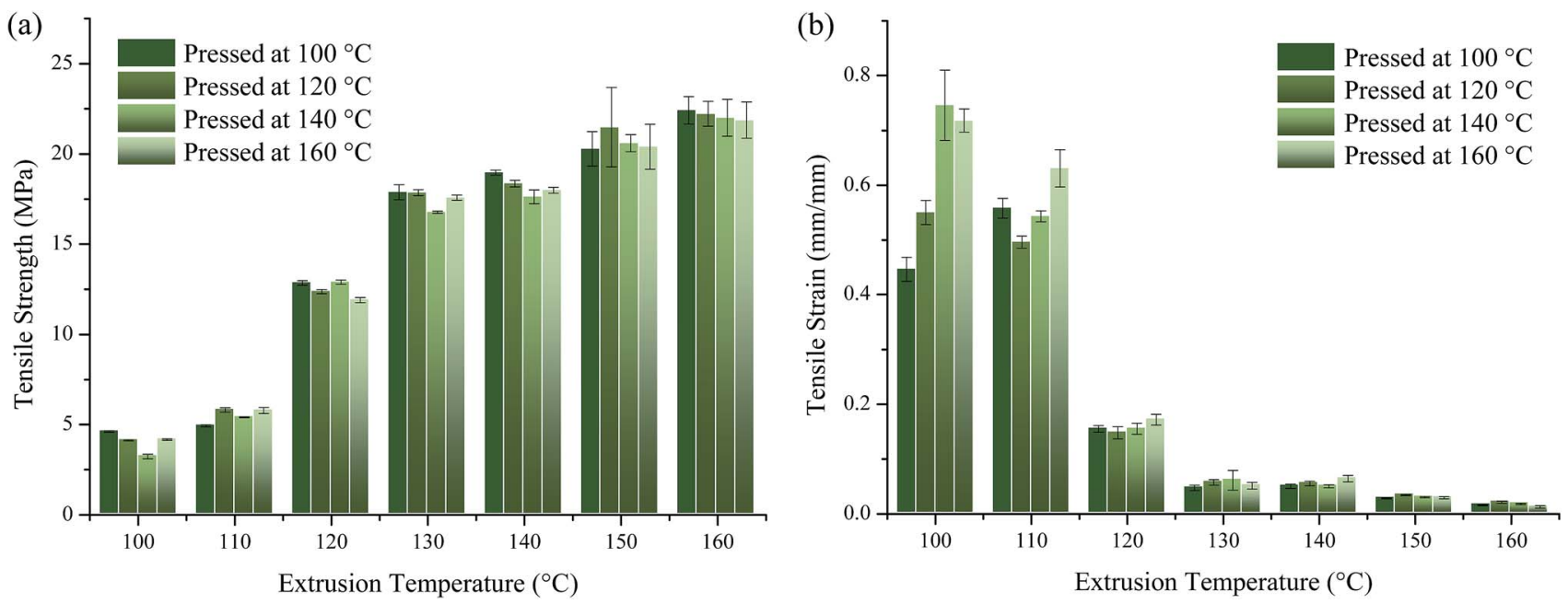

Fig. 2 The effect of pressing and extrusion temperature. (a) Ultimate tensile stress and (b) tensile strain. All samples in this table were pressed with $110 \mathrm{kN}$ for 10 minutes. Typical water content for all samples ranged from 2.2 to $2.4 \mathrm{wt} \%$.
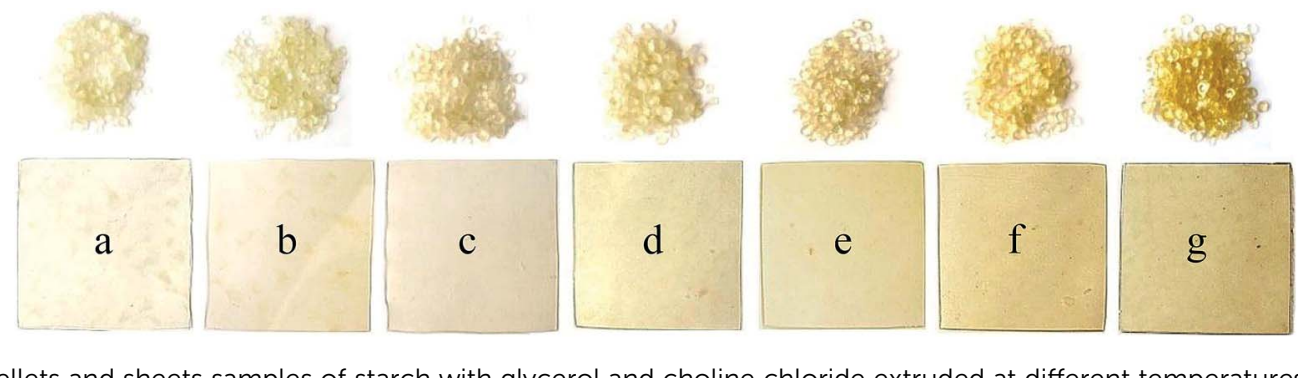

Fig. 3 Extruded pellets and sheets samples of starch with glycerol and choline chloride extruded at different temperatures (a) 100, (b) 110, (c) 120, (d) 130 , (e) 140, (f) 150 and (g) $160^{\circ} \mathrm{C}$.

mix with the starch; changing the screw speed which affects both the residence time and the shear mixing. Decreasing of the residence time and increasing shear mixing in the extruder by increasing the screw speed increases the tensile strength of TPS to some extent as shown in Table 3. However it can be seen from the data at $185 \mathrm{rpm}$, that treating the material too aggressively results in excessive degradation and the material begins to lose structural integrity.

In addition to the change in strength there is also a change in optical appearance resulting from degradation of the TPS. As the screw speed rises, frictional or shear heating increases and causes the starch granules to degrade to a small extent. Fig. 4 shows samples of extruded pellets resulting from extruding the

Table 3 The effect of extruder residence time on the tensile stress and $\%$ elongation of the starch samples. All samples were extruded at $150{ }^{\circ} \mathrm{C}$ and then pressed at $140{ }^{\circ} \mathrm{C}$ with $100 \mathrm{kN}$ force

\begin{tabular}{lll}
\hline Screw speed $(\mathrm{rpm})$ & Tensile stress $(\mathrm{MPa})$ & \% Elongation \\
\hline 110 & $20.6 \pm 0.5$ & $3.0 \pm 0.1$ \\
135 & $21.6 \pm 0.4$ & $7.4 \pm 0.8$ \\
160 & $24.2 \pm 0.8$ & $4.7 \pm 0.6$ \\
185 & $19.7 \pm 0.9$ & $3.6 \pm 0.3$
\end{tabular}

same batch of components at different screw speeds. It is clear that the samples extruded at $185 \mathrm{rpm}$ are darker than those processed at $110 \mathrm{rpm}$, despite the shorter residence time, and, as with extrusion temperature, this darker colour results in a more brittle material with a higher UTS. These observations and results could provide evidence that an increased rotation rate leads to increased shear heating that results in localised heating of the material beyond its degradation temperature.

Fig. 5 compares the DSC thermograms of TPS pellets extruded at $100{ }^{\circ} \mathrm{C}$ and $160{ }^{\circ} \mathrm{C}$, both traces demonstrate a characteristic change in heat capacity normally assigned to a glass transition $\left(T_{\mathrm{g}}\right)$. The TPS extruded at $100{ }^{\circ} \mathrm{C}$ had a $T_{\mathrm{g}}$ temperature of approximately $13{ }^{\circ} \mathrm{C}$ (Fig. 5) whilst the TPS pellets extruded at $160^{\circ} \mathrm{C}$ have a slightly higher $T_{\mathrm{g}}$ of approximately $22{ }^{\circ} \mathrm{C}$. It has previously been shown that DSC traces occasionally exhibit an upper and lower $T_{\mathrm{g}}$, a phenomenon dependent upon the amount and type of plasticiser; a low glycerol and water content leads to a single phase transition, while more plasticiser gives two glass transition temperatures. $^{15,16}$ The samples in Fig. 5 were also subjected to temperature sweeps down to $-100{ }^{\circ} \mathrm{C}$ and these did not show the second $T_{\mathrm{g}}$ observed in previous studies. No distinct melting temperatures were observed for any samples although an indication of softening can clearly be seen from the DMA data in 


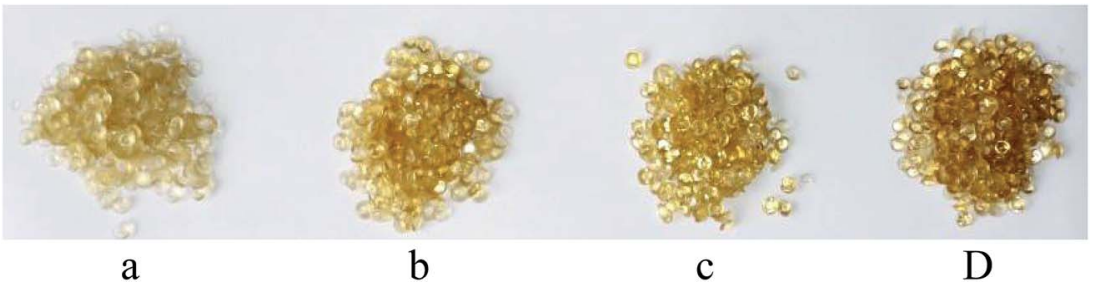

Fig. 4 Pellets extruded at different screw speeds (a) 110, (b) 135, (c) 160 and (d) $185 \mathrm{rpm}$. All samples were extruded at $150{ }^{\circ} \mathrm{C}$.

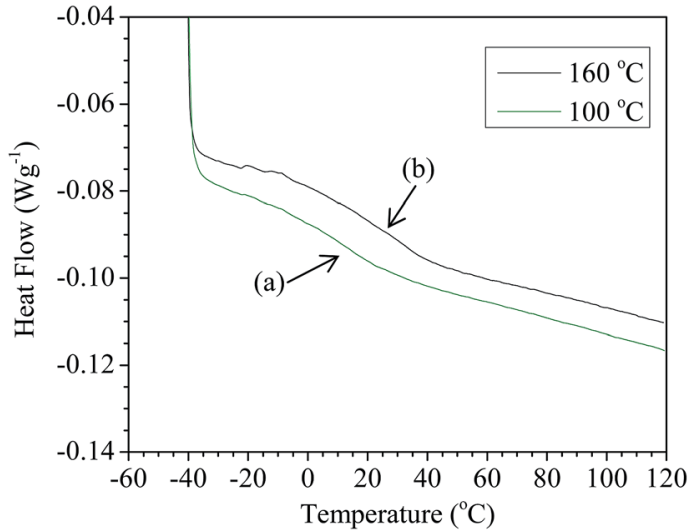

Fig. 5 A comparison of DSC results of ground TPS pellets extruded at $100^{\circ} \mathrm{C}$ (green) with a $T_{\mathrm{g}}$ of $13^{\circ} \mathrm{C}$ (a) and extruded at $160^{\circ} \mathrm{C}$ (black) with a $T_{\mathrm{g}}$ of $22^{\circ} \mathrm{C}(\mathrm{b})$.

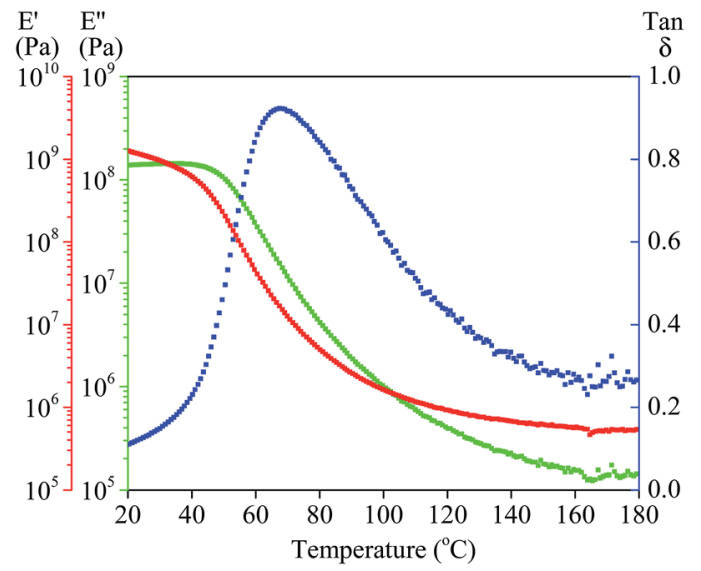

Fig. 6 DMA results of ground TPS pellets extruded at $160^{\circ} \mathrm{C}$ showing storage modulus ( $E^{\prime}$, red) loss modulus ( $E^{\prime \prime}$, green) and Tan delta $\left(E^{\prime \prime} / E^{\prime}\right.$, blue).
Fig. 6. In all cases samples show evidence of decomposition at approximately $250{ }^{\circ} \mathrm{C}$.

The main mechanical relaxation $T_{\alpha}$ associated to calorimetric $T_{\mathrm{g}}$ was also analysed by dynamic mechanical analysis (DMA) an example for which can be seen in Fig. 6 . Whilst the $T_{\alpha}$ values were marginally different to the DSC data, as is normal when looking at a tan delta, they followed a very similar trend with the higher $T_{\mathrm{g}}$ for the plastic extruded at higher temperatures. It was also important to note that the lower temperature extruded plastics had a wide temperature of mechanical relaxation where as those extruded at a higher temperature had a much narrower mechanical relaxation window.

The high shear mixing and temperature conditions increase the homogeneity of the extruded TPS, and consequently strength and transparency. Fig. 7 shows SEM images of the native corn starch and compares it with the plasticised corn starch samples extruded at different temperatures. It can be seen the notable granular structure becomes less notable after extrusion.

XRD experiments were carried out to investigate the effect of different extrusion conditions on the crystallinity of TPS. Fig. 8 shows the XRD of samples extruded at 100, 120, 130 and $160^{\circ} \mathrm{C}$ (all pressed at $140{ }^{\circ} \mathrm{C}$ ). It is immediately apparent that all three samples have some crystal structure; the shoulder at $13^{\circ}$ and $20^{\circ}$ is due to V-type structure formed by the crystallisation of complexes of amylose and lipids present in corn flour. The level of crystallinity has been determined from the ratio of integrated signal to a crystalline reference. The native starch has about $40 \%$ crystallinity whereas the material extruded at $100{ }^{\circ} \mathrm{C}$ has $10 \%$ with the degree of crystallinity increasing to approximately $15 \%$ for $130{ }^{\circ} \mathrm{C}$ and $20 \%$ as the extrusion temperature increases at $160{ }^{\circ} \mathrm{C}$. It's possible that at higher temperatures, dehydration of the amylose leads to recrystallization and results in a stronger but more brittle material. The material extruded at $100{ }^{\circ} \mathrm{C}$ also has a slightly different diffraction pattern; it is possible that this

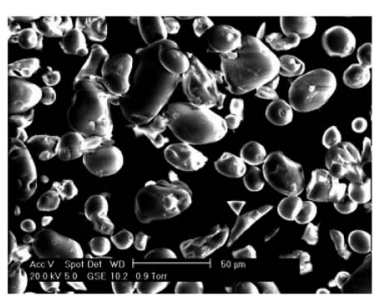

a

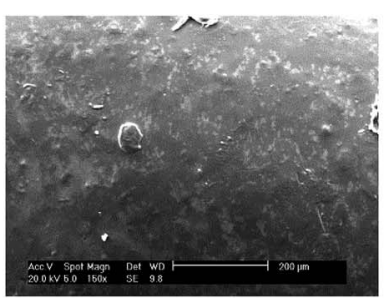

b

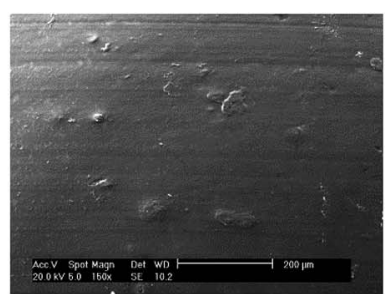

c

Fig. 7 SEM images of (a) dry corn flour and samples extruded with a screws speed of $100 \mathrm{rpm}$, and temperature of (b) $150{ }^{\circ} \mathrm{C}$, (c) $160{ }^{\circ} \mathrm{C}$. 


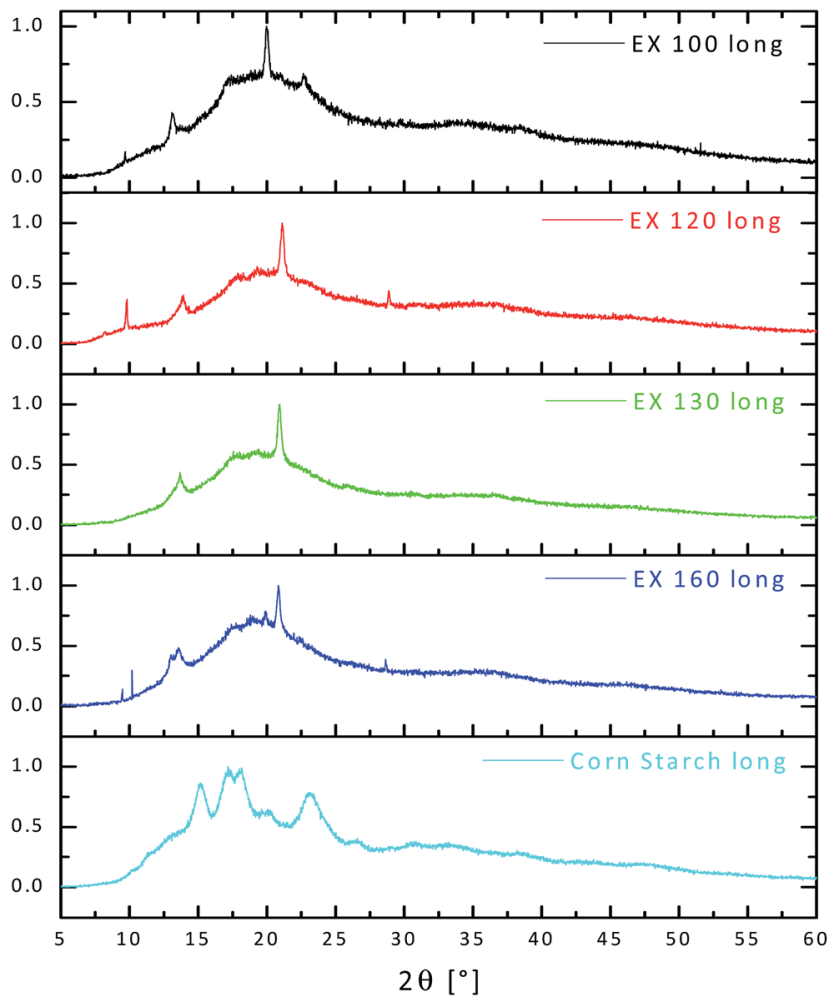

Fig. 8 XRD spectra of starch/glycerol/choline chloride extruded at $100,120,130$ and $160{ }^{\circ} \mathrm{C}$ together with that for plain corn starch.

is due to some sort of phase transition between $100{ }^{\circ} \mathrm{C}$ and $120{ }^{\circ} \mathrm{C}$ during the extrusion process.

The absence of the B type crystalline form in all samples is particularly interesting since this type of recrystallization is known to be responsible for the so called retrogradation of starch based plastics which results in progressive embrittlement during aging. ${ }^{17}$

As can be seen in Fig. 8 the XRD results show that there is little or no native corn starch present in any of the extruded samples; this is in agreement with visual and physical observations, tensile data and data obtained from the SEM.

The moderate softening temperature shown in Fig. 6 shows that the salt modified starch could be suitable for injection

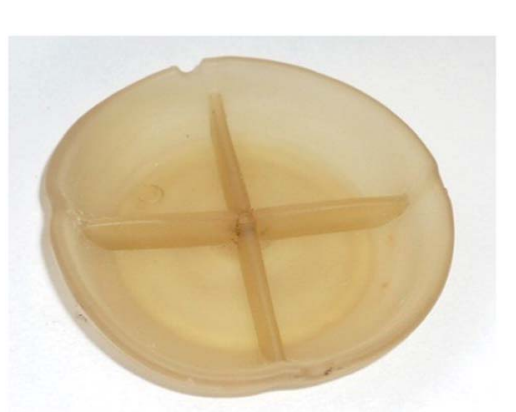

Fig. 9 Sample of starch plasticised with glycerol and choline chloride injection moulded into a $10 \mathrm{~cm}$ mould $\left(200^{\circ} \mathrm{C}\right.$ and 60 bar). Sample diameter $7 \mathrm{~cm}$. moulding. As can be seen from Fig. 9, a simple paint mixing pot was injection moulded further enhancing the application of the material. Interestingly, despite the high temperature required for injection moulding the sample there were no visual signs of degradation. We propose that this is due to a lack of mechanical agitation and thus shear heating when compared to extrusion with a twin screw extruder.

\section{Conclusion}

It has been shown that thermoplastic starch, based on corn starch with glycerol and choline chloride as a plasticiser, can be formed and is mechanically comparable to polyolefin-based thermoplastics. TPS has acceptable mechanical properties for many applications especially when used for a short-time. It was found that the physical properties of TPS can be controlled by the processing conditions and that water content is critical as is the extrusion temperature. The pressing time and temperature are relatively unimportant so it can be deduced that the extrusion conditions are vital in controlling the ability of the salt to plasticise the starch/glycerol mixture. In all processing and composition conditions a small amount (3-4\%) of material was still crystalline.

\section{Acknowledgements}

The authors would like to thank EPSRC (EP/F016301/1 and EP/ H048553/1), and the Royal Society Brian Mercer Award for funding this study. The Saudi Arabian Ministry of Higher Education are also acknowledged for funding a studentship to Tariq Abolibda.

\section{References}

1 L. P. Janssen and L. Moscicki, Thermoplastic Starch: A Green Material for Various Industries, Wiley-VCH, Weinheim, 2009.

2 D. Lourdin, L. Coignard, H. Bizot and P. Colonna, Polymer, 1997, 38, 5401-5406.

3 Y. Zhang, C. Rempel and Q. Liu, Crit. Rev. Food Sci. Nutr., 2014, 54, 1353-1370.

4 R. Shanks, I. Kong, Thermoplastic Elastomers, ed. A. Z. ElSonbati, Intech publishing Rijeka, Croatia, 2012, pp. 95-116.

5 C. Barron, B. Bouchet, G. Della Valle, D. J. Gallant and V. Planchot, J. Cereal Sci., 2001, 33, 289-300.

6 W. C. Liu, P. J. Halley and R. G. Gilbert, Macromolecules, 2010, 43(6), 2855-2864.

7 F. Berzin, A. Tara, L. Tighzert and B. Vergnes, Polym. Eng. Sci., 2010, 50(9), 1758-1766.

8 A. P. Abbott, A. D. Ballantyne, J. Palenzuela Conde, K. S. Ryder and W. R. Wise, Green Chem., 2012, 14, 13021307, DOI: 10.1039/c2gc16568f.

9 E. Leroy, P. Decaen, P. Jacquet, G. Coativy, B. Pontoire, A. Reguerre and D. Lourdin, Green Chem., 2012, 14, 30633069, DOI: 10.1039/C2GC36107H.

10 A. P. Abbott, J. Palenzuela Conde, S. Davis and W. R. Wise, Green Chem., 2012, 14, 3067-3070. 
11 A. P. Abbott, R. C. Harris, K. S. Ryder, C. D'Agostino, L. F. Gladden and M. D. Mantle, Green Chem., 2011, 13, 82-90.

12 T. Abolibda, MSc, University of Leicester, 2011.

13 M. Pagliaro and M. Rossi, The Future of Glycerol, Royal Society of Chemistry Publishing, Cambridge, 2010.

14 G. Dogossy and T. Czigany, J. Reinf. Plast. Compos., 2011, 30, 1819-1825, DOI: 10.1177/0731684411429728.
15 A. A. S. Curvelo, A. J. F. de Carvalho and J. A. M. Agnelli, Carbohydr. Polym., 2001, 45, 183-188.

16 P. M. Forssella, J. M. Mikkilti, G. K. Moates and R. Parker, Carbohydr. Polym., 1997, 34, 275-282.

17 J. van Soesta and J. Vliegenthart, Trends Biotechnol., 1997, 15, 208-213. 